\title{
Strengthening institutional capacity for equitable health research: lessons from Latin America and the Caribbean
}

\author{
Marshall Tulloch-Reid and colleagues argue that development of research capacity in Latin \\ America and the Caribbean requires investment in both individuals and regional institutions
}

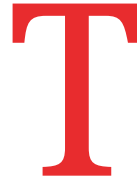
he political, economic, environmental, and social determinants of health now receive greater recognition. This had led to an increased demand for global health research involving low and middle income countries, to meet the United Nations sustainable development goals. ${ }^{1}$ In addition to funding, sufficient human resources and infrastructure are needed so that these countries become equal partners with internationally recognised research institutions in high income countries that set research agendas and ensure that the global health research programme reflects their needs. Constrained research capacity and large disparities between high income countries and low and middle income coun-

\section{KEY MESSAGES}

- Sustainable development of human resources requires institutional strengthening and development of interdisciplinary research teams, not just training of individual scientists

- Employing and empowering local institutions that can adapt training to meet local and international needs is a critical factor in improving research in low and middle income countries worldwide

- Fair, respectful, and strategic partnerships, together with financial investments in infrastructure, are necessary for implementing and maintaining sustainable training programmes in low and middle income countries

- Investments by national and international funding agencies in human resources and research career opportunities and physical infrastructure for health research are needed

- Formal evaluation of the success of training in low and middle income countries in Latin America and the Caribbean is necessary to better demonstrate its effect on health and research equity and encourage additional support for these efforts tries in their capacity to produce and use research for health have contributed to a lack of evidence to inform practice and guide regional and global health policy. This has perpetuated health inequalities. $^{2}$

In some Latin American countries research has increased, but several Caribbean territories are among those with the lowest level of medical research outputs. ${ }^{3}$ Through their Policy on Research for Health, the Pan-American Health Organization (PAHO), regional office of the World Health Organization (WHO), advocates strengthening in-country research in all member states to promote equity in health and socioeconomic development. ${ }^{2}$

We describe outcomes and lessons learnt from three case studies, identified by PAHO. These describe the approaches taken to develop research capacity in Latin America and the Caribbean. The first study describes building research capacity by North-South collaboration and is an example of Latin American networking. The second study was initially developed through bilateral cooperation followed by national and international networking. It has become a model for South-South collaboration. The third case study uses multiple approaches to build on existing infrastructure. It is an example of technical cooperation between PAHO and the English-speaking Caribbean.

\section{North-South collaboration: the International Clinical Epidemiology Network (INCLEN)}

In the 1980s, the Rockefeller Foundation sponsored the creation of INCLEN to bridge the divide between public health and clinical medicine, to improve health in developing countries. ${ }^{4}$ INCLEN provided young clinical faculty members from medical schools in South East Asia, China, India, Africa, and Latin America with scholarships in North America and Australia to receive masters level clinical epidemiology training. ${ }^{4}$

The Rockefeller Foundation soon realised that supportive academic centres in countries other than North America and Australia were needed to sustain this INCLEN initiative. It formed partnerships with local medical and public health schools and provided financial support to establish clinical epidemiology units, encouraging the development of expertise in biostatistics, health economics, and social sciences. ${ }^{45}$ The foundation also provided leadership and management training. ${ }^{4}$ Several clinical epidemiology units were established over a period of 10 years. These became regional centres of excellence for training and research, with teams able to respond to regional research needs. To enhance regional collaboration initiatives, the Latin American Clinical Epidemiology Network (LatinCLEN) was created in 1991.

LatinCLEN was not successful everywhere, but is now present in seven countries. Its member institutions provide training in clinical epidemiology, biostatistics and health economics, including one doctoral and nine masters programmes. LatinCLEN has dealt with regional needs and carried out high impact research in mental health, maternal and child health, health economic evaluation, systematic reviews, programme evaluation and clinical practice guidelines (box 1). Over the past 20 years it has successfully influenced and led cooperation with the Cochrane and Campbell collaborations.

South-South collaboration: CIDEIM-regional training centre in the Americas

The Centro Internacional de Entrenamiento e Investigaciones Médicas (CIDEIM) in Colombia is a good example of a NorthSouth bilateral partnership evolving into a model for South-South collaboration. The centre originated as a bilateral technical assistance mission in 1961 supported by a grant to Tulane University from the US National Institutes of Health. ${ }^{7}$ The centre was broadly dedicated to health research. It formed a partnership with the Universidad del Valle Faculty of Medicine and was located within its campus until 1974. At this time COLCIENCIAS, the Colombian national agency for promotion and financing of science and technology, assumed the co-direction with Tulane University. Multilateral funding of research and institutional grants awarded during the 1980 s by COLCIENCIAS and international agencies laid the foundation for transition of CIDEIM to a non-profit Colombian biomedical research institution in 1990 through a public-private 


\section{Box 1: The Latin American Clinical Epidemiology Network (LatinCLEN)}

LatinCLEN aims at strengthening national and regional health systems through research into the effectiveness and efficiency of health interventions and the determinants of health and disease. Since its inception, LatinCLEN centres have trained over 400 clinical epidemiologists and produced over 1200 scholarly outputs. ${ }^{6}$ LatinCLEN centres and their members have provided leadership in making economic assessments of health interventions. They have refined methods for linking clinical practice guidelines with health economic evaluation, and set standards for evaluating economic evidence from different sources. The network has influenced health and research policies and the work of development agencies and intergovernmental organisations in the region.

LatinCLEN's research includes:

- Development and validation of economic models to evaluate the disease burden of smoking, and the cost effectiveness of tobacco control interventions in Argentina and in six other countries in 2011 (LatinCLEN Tobacco Research Group)

- Economic evaluation of exercise based cardiac rehabilitation programmes for patients with chronic heart failure in Colombia in 2016

- Determination of the impact of the Kangaroo Mother Care Program in Colombia

- Evaluation of the cost effectiveness of new drugs for patients with atrial fibrillation and acute coronary syndrome in Chile ${ }^{6}$

initiative. National commitment was crucial for each stage of CIDIEM's evolution. In 2009 CIDEIM was selected to be the regional training centre in the Americas by the Special Programme for Research and Training in Tropical Diseases (TDR). The regional training centres collaborate in improving the scientific quality and competitiveness of health research in low and middle income countries. ${ }^{89}$

In CIDEIM, interdisciplinary teams design and conduct basic, translational, applied and implementation research in partnership with public health authorities, universities and communities. Ongoing projects allow trainees to conduct supervised research alongside national and international investigator teams. Hands on research is complemented by skill building courses, which may be face to face, in a virtual format, or a combination of the two. The courses include data management, project planning, good clinical practice, data analysis planning, information and communication technology in health research, research ethics, and scientific integrity. This approach promotes compliance of research with international standards and participation in national and international research agendas. An important aspect of the courses is their design for replication through training of trainers and collaboration with regional network institutions to develop and adapt training modules.

As a regional training centre, CIDEIM's strategy for building capacity is aimed at institutions (box 2). PAHO assists in identifying institutional participants and contributes logistical support for regional dissemination. Since 2009, CIDEIM has trained more than 2000 investigators, transferred training capacity to network institutions in Central and South America and the Caribbean and conducted interregional training in collaboration with regional training centres in Indonesia, Kazakhstan, and Ghana. ${ }^{10}$

\section{Institutional strengthening through North- South and South-South collaboration: University of the West Indies clinical epidemiology unit}

The University of the West Indies (UWI) epidemiology research unit was established in 1999 as part of the Tropical Medicine Research Institute, now the Caribbean Institute for Health Research (CAIHR). The need for regional training in epidemiology was recognised by the unit, which launched an MSc programme in 2005, followed by a $\mathrm{PhD}$ programme.

In May 2007, participants at PAHO's 40th Meeting of the Advisory Committee on Health Research proposed developing a team of epidemiologists to increase the production and use of evidence to inform public health policy in the Caribbean. ${ }^{11}$ PAHO's delegates committed to supporting links between INCLEN and the University of the West Indies. The meeting became the catalyst for a series of developments, with the epidemiology research unit as its focal point.

The UWI clinical epidemiology unit (UWI/CEU), established in February 2009, comprised faculty members from the epidemiology unit and other university departments. ${ }^{12}$ Members completed a training course, entitled "Effective project planning and evaluation in biomedical research," run by CIDEIM across Latin America and the Caribbean. ${ }^{9}$ An important capacity building feature of the course is the training of local participants to deliver the course, allowing UWI to replicate the training in Jamaica and other settings. The unit has subsequently provided training in project planning and evaluation in biomedical research for over 200 Caribbean professionals. The methodology has been incorporated into graduate degree courses at UWI and St George's University, Grenada. ${ }^{13}$ UWI staff have also received training in knowledge synthesis and translation of research into practice. This facilitated the launch of Cochrane Caribbean in June $2013^{14}$ (box 3).

These skills and experiences have helped strengthen UWI's epidemiology programme. It has produced 19 epidemiologists able

\section{Box 2: Centro Internacional de Entrenamiento e Investigaciones Médicas (CIDEIM)}

Training is essential to the mission and research programme of CIDEIM. Research capacity is developed through a range of training approaches. These build upon and complement postgraduate programmes at national universities. Ongoing research provides a platform for mentored clinical, laboratory, and field research from the predoctoral to postdoctoral stages. Importantly, faculty members and students participate in research skill building courses and web based elective postgraduate courses.

Since 2007, support has been received from the Global Infectious Disease Research Training Programme of the US National Institutes of Health Fogarty International Center for semester long, web based, postgraduate courses. These have covered advanced topics relevant to biomedicine and health science and have been organised and hosted by CIDEIM in collaboration with the Yale University School of Public Health. Live lectures and discussions are conducted virtually by national and international experts, and courses are registered for credit as electives within postgraduate programmes at participating universities. Course materials, including recorded lectures and evaluations, are accessed and managed using the open source learning Moodle platform. Over 1000 investigators and trainees from 30 Colombian universities, 12 institutes, health sector institutions, industry, and 17 Latin American and Caribbean regional universities/institutes have participated in these elective courses. 
Box 3: University of the West Indies clinical epidemiology unit (UWI/CEU)

Through training placements for UWI/CEU PhD candidates at the University of Ottawa and Johns Hopkins University, a special interest in systematic reviews and evidence based healthcare was developed.

This led to the first training workshop in systematic review methodology in Jamaica in March 2012 (supported by faculty from the UWI/CEU, the University of Ottawa Centre for Global Health and PAHO) and the subsequent launch of Cochrane Caribbean in June 2013.

Cochrane Caribbean, together with members of the UWI/CEU, have hosted annual Cochrane training workshops within the Caribbean Institute for Health Research and provided technical support for English speaking Caribbean territories. The centre also facilitates links between local and international researchers and provides training on systematic reviews and evidence-based healthcare for undergraduate and graduate students. Cochrane Caribbean has supported the development and completion of four systematic reviews initiated by local investigators, collaborated on over 20 systematic reviews, and provided evidence for the development of regional and national policy-most recently, in food industry policy and medication formularies.

to deal with regional research needs in academia, health administration and delivery, and policy making. ${ }^{15}$ Initially, many candidates pursued training to enhance performance in existing posts or fill vacant positions. Now, greater emphasis is placed on providing research development opportunities and career paths to encourage graduates to remain in the Caribbean.

\section{Challenges to sustaining capacity building}

Financial support to maintain many of these initiatives is insufficient. Loss of support from the Rockefeller Foundation has significantly restricted the activities of INCLEN and LatinCLEN. PAHO contributes to the regional training initiatives of CIDEIM and UWI/CEU, through support of workshops and investigator exchanges. However, training and capacity building depend on stable institutional funding and career opportunities that will attract new generations of health researchers. Key personnel at UWI/ CEU and virtually all personnel in CIDEIM are dependent on funding for projects. This means that delivery of project results must be balanced with capacity building activities, which is a challenge to sustainability. Additionally, critical shortages of skilled personnel remain in some fields, including biostatistics, implementation science, research management, and health economics. Capacity building currently focuses on human resources, but there is also a critical need for investment in, and renewal of, institutional infrastructure.

\section{Discussion}

The case studies presented here illustrate distinct approaches to developing research capacity in low and middle income countries. ${ }^{16}$ These include vertical research projects where investigators from high income countries lead and conduct targeted research in low and middle income countries; centres of excellence concentrating investment in a few institutions; NorthSouth partnerships focusing on a specific research question and networks and consortiums linking multiple research institutions with complementary skills to deal with research challenges. ${ }^{16}$ Each case study used combinations of all approaches over time to build individual and institutional capacities.

Although vertical projects can meet project objectives, they do not usually produce sustainable capacity in low and middle income countries once completed. INCLEN initially focused on building capacity through individual scholarships. However, it found that strengthening institutions by creating clinical epidemiology units with multidisciplinary teams was critical for sustaining gains in capacity development and retaining talent. ${ }^{4}$

CIDEIM's experience illustrates how North-South collaborations can lead to enduring centres of excellence. CIDEIM has evolved over 57 years to become a centre of innovative research capacity building with regional and global influence. Through partnership with PAHO and Latin American and Carribean regional institutions, CIDEIM provides a cost sharing model for research training. Incorporation of the content of short courses on good research practices into the curriculums of postgraduate programmes in the region further extends and sustains research capacity building.

UWI/CEU illustrates use of a combination of capacity building measures to build regional institutional capacity. Locating the UWI/ CEU at CAIHR, an institution whose primary role is producing research, has been critical in allowing practitioners protected time for research. PAHO, together with regional and international partners, by supporting UWI/CEU in building a team of regional epidemiologists in the Caribbean, has enabled a larger and more sustainable impact. ${ }^{13}$

The current constraints on national and international funding for research do not encourage investment in building local in-country capacity, which requires many years of sustained support. Latin American and Caribbean research networks continue to look to North-South collaborations for funding. A recent systematic review that examined research capacity development found that most research on North-South collaborations focused on problems with these relationships. Many publications argued that too few benefits accrue to the southern partner. ${ }^{16}$
Several organisations worldwide call for capacity building to be a key component of global research funding to reduce "brain drain" from low and middle income countries. ${ }^{17}$ Stable research career opportunities are a major determinant of sustainable research and research training capacity. Funding schemes for capacity building could strategically leverage existing strengths in Latin American and Caribbean institutions. A postdoctoral funding scheme for low and middle income countries could begin to deal with this critical transition stage in career development, particularly in this region where most countries have postgraduate training programmes.

Some international agencies have instituted funding schemes that target research teams in low and middle income countries. These include the International Research in Infectious Diseases and Tropical Medicine Research Centres grant schemes of the US National Institutes of Health, and Fogarty training programmes. The Wellcome Trust offers a range of international fellowship programmes, collaborative projects and even multi-user equipment grants. ${ }^{18}$

Institutions in low and middle income countries, particularly those in Latin America and the Caribbean, need to improve their ability to provide consistent accurate forecasts of total research costs to funding agencies and to obtain adequate reimbursement of indirect costs. ${ }^{2021}$ Some funding agencies recognise the constraints imposed by limited support for operational costs and are willing to negotiate higher indirect costs for such institutions; others, however, cap these resources at a lower rate than for high income countries. ${ }^{19}$ Severely restricting indirect costs has a negative impact on administrative support and capital expenditure on infrastructure and equipment. It is a disincentive for investigators and faculty to participate in non-profit training activities. Institutions in low and middle income countries need this support to achieve recognition as credible focal points for creating and sustaining change. ${ }^{20}$

National and regional solutions to financing institutions in Latin America and 
the Caribbean include investment in their own capacity development by dedicating a proportion of national budgets or special taxation to finance research and research infrastructure. There is also an opportunity for collaboration with scientists of the national research diaspora. ${ }^{17}$ In addition to dealing with urgent health problems, improving the assessment of the pivotal role that research institutions play in national development may encourage policy makers to recognise research for health as an investment rather than an expense. $^{2}$

\section{Conclusions}

Despite the diverse challenges of building research capacity in low and middle income countries, the three case studies presented here show that positive outcomes through coordinated use of existing networks and limited funds are possible. They also highlight the importance of North-South and South-South collaboration in increasing research capacity to improve health throughout the Americas. Key components of their success include supporting committed leaders, providing training by building upon existing regional training initiatives and creating good regional and international partnerships. The presence of capable research institutions in Latin America and the Caribbean will be crucial for sustainable and equitable research for health in the future.

Contributors and sources: All authors have led or facilitated many of the initiatives described in this paper and participated in conceptualising, drafting and revising the text, approving the final version of the article submitted for publication, and are accountable for all parts of the work they have contributed. MKT-R is the guarantor of the article.

Competing interests: We have read and understood BMJ policy on declaration of interests and have no relevant interests to declare.

Provenance and peer review: Commissioned; externally peer reviewed.

This article is part of a series proposed by PAHO and commissioned by The BMJ, which peer reviewed edited, and made the decision to publish the article with no involvement from PAHO. Open access fees for the series are funded by PAHO

Marshall K Tulloch-Reid, professor ${ }^{1}$

Nancy Gore Saravia, director ${ }^{2,3}$

Rodolfo J Dennis, professor ${ }^{4}$
Andres Jaramillo, coordinator research and training portfolio $^{2,3}$

Luis Gabriel Cuervo, senior adviser, health systems research 5

Susan P Walker, professor ${ }^{1}$

Luis Alejandro Salicrup, senior adviser for global health research ${ }^{5,6}$

${ }^{1}$ Caribbean Institute for Health Research, University of the West Indies, Kingston, Jamaica

${ }^{2}$ Centro Internacional de Entrenamiento e Investigaciones Médicas, Cali, Colombia

${ }^{3}$ Universidad Icesi, Cali, Colombia

${ }^{4}$ Departamento de Epidemiología Clínica y Bioestadística, Pontificia Universidad Javeriana, Bogotá, Colombia

${ }^{5}$ Health Services and Access Unit, Department of Health Systems and Services of the Pan American Health Organization/World Health Organization, Washington DC, USA

${ }^{6}$ Center for Global Health, National Cancer Institute, United States National Institutes of Health, USA

Correspondence to: M KTulloch-Reid marshall.tullochreid@uwimona.edu.jm

1 World Health Organization. Closing the gap in a generation: health equity through action on the social determinants of health. Final Report of the Commission on Social Determinants of Health. 2008. http://www.who.int/social_determinants/ thecommission/finalreport/en/

2 Pan American Health Organization/World Health Organization. PAHO Policy on Research for Health. Document CD49/10 of the 49th session of PAHO's Directing Council. 2009. https://www.paho.org/hq/ index.php?option=com_content\&view=article\&id $=1$ 414\%3A2009-policy-on-research-health\&catid=25 02\%3Apublications\&lang=en

3 McKee M, Stuckler D, Basu S. Where there is no health research: what can be done to fill the global gaps in health research? PLoS Med 2012;9:e1001209. http://journals. plos.org/plosmedicine/article?id=10.1371/ journal.pmed.1001209. doi:10.1371/journal. pmed.1001209

4 Halstead SB, Tugwell P, Bennett K. The International Clinical Epidemiology Network (INCLEN): a progress report. / Clin Epidemiol 1991;44:579-89. doi:10.1016/0895-4356(91)90222-U

5 Morrow RHJr, Lansang MA. The role of clinical epidemiology in establishing essential national health research capabilities in developing countries. Infect Dis Clin North Am 1991;5:235-46.

6 Gómez Restrepo C, Muñoz N S, Ruiz AJ, Lanas F. Latin American Clinical Epidemiology Network Series Paper 1: The Latin American Clinical Epidemiology Network “LatinCLEN". J Clin Epidemiol 2017;86:71-4. doi:10.1016/j.jclinepi.2016.10.002

7 Board on Science and Technology for International Development, Institute of Medicine National Academy of Sciences. The US capacity to address tropical infectious disease problems. National Academy Press, 1987. https://books.google.co.uk/ books?id=CpYrAAAAYAAJ\&pg=PR2\&lpg=PR2\&d $q=$ The+US+Capacity+to+Address+Tropical+Infe ctious+Disease+Problems.+National+Academy+ of + Science+1987.+Report+No.\&source=bl\&ots

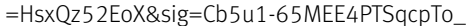
d4YOMY\&hl=en\&sa $=X \&$ redir_esc $=y$

8 World Health Organization. Regional training centers. An introduction to the TDR network. 2015. www.who. int/entity/tdr/news/2015/en/

9 Ogundahunsi OA, Vahedi M, Kamau EM, et al. Strengthening research capacity-TDR's evolving experience in low- and middle-income countries. PLoS Negl Trop Dis 2015;9:e3380. doi:10.1371/ journal.pntd.0003380http://journals.plos. org/plosntds/article?id=10.1371/journal. pntd.0003380.

10 Alger J, Gómez L, Jaramillo A, Saravia NG, Cuervo LG. Reunión de la Red Inter-Regional de Planeación y Evaluación Efectivas de Proyectos de Investigación para la Salud, Cali, Colombia, Abril 2010. Rev Med Hondur 2010;78:97-100. http://www.paho.org/hq/ index.php?option=com_docman\&task=doc_view\&gi $\mathrm{d}=17086$ \&ltemid $=270$ \&lang=en

11 Advisory Committee on Health Research (ACHR). Pan American Health Organization/World Health Organization (PAHO/WHO). 40th ACHR: An overview of health research policy in the Americas and a proposal for PAHO/WHO's research policy. 2007. http://www1.paho.org/english/DD/IKM/RC/ACHR2007-40-05-Policy.pdf?ua=1

12 University of the West Indies. UWI admitted to International Epidemiology Network. Press release. https://www.mona.uwi.edu/marcom/uwinotebook/ entry/3492

13 Pan American Health Organization/World Health Organization. Report on strengthening research capacities for health in the Caribbean, 2007-2017. Washington, DC: PAHO/WHO, 2017. http://iris.paho. org/xmlui/handle/123456789/34342

14 Cochrane Caribbean. Cochrane Caribbean launch. Press release, 2013. http://caribbean.cochrane.org/ cochrane-caribbean-launch

15 Tulloch-Reid MK. The University of the West Indies Clinical Epidemiology Unit: collaborating to improve health. J Clin Epidemiol 2015;68:1099-100. doi:10.1016/j.jclinepi.2015.04.012

16 Franzen SR, Chandler C, Lang T. Health research capacity development in low- and middle-income countries: reality or rhetoric? A systematic metanarrative review of the qualitative literature. BMJ Open 2017;7:e012332. doi:10.1136/ bmjopen-2016-012332.

17 Saravia NG, Miranda JF. Plumbing the brain drain Bull World Health Organ 2004;82:608-15.

18 Wellcome Trust. Scheme finder. United Kingdom: Research Council UK, 2018. https://wellcome.ac.uk/ funding/scheme-finder

19 United States National Institutes of Health. NIH grants policy statement. 2017. https://grants.nih.gov/grants/ policy/nihgps/html5/section_7/7.4_reimbursement of_facilities_and_administrative_costs.htm

20 Lucas S. How to fund think tanks effectively even when you can't William and Flora Hewlett Foundation, 2017. https://www.hewlett.org/fundthink-tanks-flexibly-even-cant/

21 Council on Health Research and Development. Fair research contracting. Geneva, Switzerland, 2018. http://www.cohred.org/frc/

Cite this as: $B M J$ 2018;362:k2456

http://dx.doi.org/10.1136/bmj.k2456

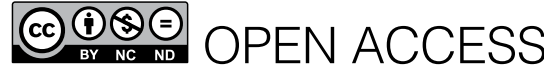

This is an Open Access article distributed under the terms of the Creative Commons Attribution Non Commercial No Derivs IGO License (CC BY-NC-ND 3.0 IGO), which permits distribution and reproduction for non-commercial purposes in any medium, provided the original work is properly cited. If you remix, transform, or build upon the material, you may not distribute the modified material. See: https://creativecommons. org/licenses/by-nc-nd/3.0/igo/ In any reproduction of this article there should not be any suggestion that PAHO or this article endorse any specific organisation or products 